Biologie der Tiere Deutschlands

Herausgegeben von Prof. Dr. Paul Schulze. Lief. 37. Teil 26: Orthopteroidea II, Phasmodea, Saltatoria. Von Max Beier. Pp. 233-415. 16.50 gold marks. Lief. 38. Teil 9: Acanthocephala, Kratzer, von Friedrich Bock; Teil 31: Hemiptera III, von Herman Weber. Pp. 9+209-355. 16.50 gold marks. (Berlin : Gebrüder Borntraeger, 1934-1935.)

THE first portion contains two chapters, one dealing with the Phasmids (stick insects and their allies) and the second the Saltatoria (locusts, crickets, etc.). While other forms are mentioned in the first chapter, it is largely built round Carausius morosus. It includes a good account of the anatomy and histology, particularly of the sense organs, but all dealt with in correlation with function. In addition, the reproductive activities and the reactions of the animal are adequately discussed. The second chapter, which deals with the subject matter in the same manner, actually treats of a number of different species and so has a wider basis.

The second portion deals with two separate groups, the Acanthocephala and certain Hemiptera. The structure and life-histories, including the relationship between parasite and host, are very clearly set forth in some of the better known Acanthocephalids. In the introduction, the classification employed is given, and a few pages farther on is a useful list of fiftyeight worms with their final hosts and, where known, the first and second intermediate hosts also. From this it is clear that in many instances the individual species of parasites show a very wide choice of hosts.

The section on the Hemiptera is subdivided into the Aphids and the Coccids. After a satisfactory review of the morphology of the group illustrated by reference to a series of types, there follows a very useful discussion of the life-cycle of these interesting insects. Much of the information is set forth in the form of diagrams, which facilitate comparisons between the different life-histories. While the part relating to the Coccids is somewhat shorter than that relating to the Aphids, it nevertheless covers the ground adequately.

A good feature of all these contributions is the close correlation between the morphological and functional aspects of the problems. The animals are treated as living units so that the series well merits its title of 'Biology'. All the illustrations are well chosen and well reproduced; the information is up to date and the several chapters are furnished with good bibliographies.

\section{Geometrical Optics}

By Dr. H. T. Flint. Pp. ix + 266. (London : Methuen and Co., Ltd., 1936.) $7 s, 6 d$.

Dr. Frint has accomplished a task which leaves teachers of opties very much in his debt. He has produced an elementary treatise which begins at the very beginning of the subject, expounds a rule of signs lucidly and fully, and, after discussing in sufficient detail the topics associated with an intermediate course in optics, goes on to treat of thick lenses, combinations of lenses, aberrations of various kinds, apertures, photometry and optical instru- ments. Under the last heading are given brief but adequate discussions of the microscope and telescope, the eye and its defects, eyepieces, resolving powers, and various photographic objectives. Those of us who were trained in the optics of a generation ago will recognize the debt that the author owes (and acknowledges) to Drude, whose treatment of the one-to-one correspondence between points in the object- and the image-space is, in general, followed.

That Dr. Flint is the author is sufficient guarantee of the clarity and elegance of the treatment of the subject, and one of the chief virtues of the book is that it leaves the student with nothing to unlearn, whatever may be the direction of his subsequent studies in optics.

Here and there are examples of treatment concerning which divergencies of opinion are permissible. Thus, in discussing focal lines the author very naturally bases his treatment on the properties of lines of curvature-it is the method of approach natural to the mathematician. So far as the average student is concerned, the reviewer finds that method of approach most useful which is based on the properties of the caustic ; this, however, is a very minor matter.

If a suggestion may be made, it is that, in a future edition, a few laboratory exercises might with advantage be added, and that, in the exposition of the properties of the cardinal points, the Bravais points should not be forgotten.

The book may be unreservedly recommended to students in the final or junior honours grade in the universities.

\section{Physical Chemistry for Colleges :}

a Course of Instruction based upon the Fundamental Laws of Chemistry. By Prof. E. B. Millard. (International Chemical Series.) Fourth edition. Pp. ix +524. (New York and London: McGraw-Hill Book Co., Inc., 1936.) $21 s$.

WrITTEN, for the main part, in terms of the classical thermodynamic and statistical theory, the fourth edition of this book, nevertheless, gives adequately the facts of recent discoveries. Chapters involving numerical work are pleasingly free from ambiguity, so that the student should find little difficulty in working through the excellent assortment of problems appended to these chapters, although these exercises would probably be more helpful if the answers were provided.

In his treatment of modern physico-chemical theory, Prof. Millard is sound rather than provo. cative. Thus, while the existence of activated molecules is deduced as a result of the breakdown of the kinetic theory of reaction, their position in the electro-chemical theory of valency is only briefly mentioned. In the same way, heterogeneous reactions, treated largely as an application of the Phase Rule, might well have been correlated with the modern theories of adsorption and catalytic activation. Minor drawbacks of the book include the lack of formal definition, for example, of heat of reaction, order of reaction, etc., and the ambiguous use of the terms atomic weight, gram-molecular weight, etc. 